\title{
SALES LABORATORY CONCEPT FOR PROBLEM SOLVING BASED LEARNING: THE EXPERIENCE OF THE BALTIC COUNTRIES
}

\author{
Daina Znotina', Maris Igavens ${ }^{2}$ \\ ${ }^{1}$ Mg.soc.sc., lecturer, researcher, Rezekne Academy of Technologies, Rezekne, \\ Latvia, e-mail: Daina.Znotina@rta.lv \\ ${ }^{2}$ Mg.soc.sc., assistant researcher, Rezekne Academy of Technologies, Rezekne, \\ Latvia, e-mail: Maris.Igavens@rta.lv
}

\begin{abstract}
Very often youth faces many difficulties when trying to enter the labour market. It is because of lack of experience, insufficient vocational education, inadequacy between professional education and requirements for specialists in the job market. It is necessary that students get competencies and skills needed for the labour market and increase their employment possibilities. Rezekne Academy of Technologies implemented a project, where one of the objectives was integration of problem-based learning (PBL) into study processes. The aim of the research study is to investigate problem-based learning experiences among students and lecturers. Research methods - the monographic method, the analysis and survey methods. Problem-based learning is much more exciting for students and faculty than traditional learning, but it is also more time consuming and expertise intensive.
\end{abstract}

Keywords: entrepreneurs, problem-based learning, students, teaching staff. JEL code: A22, I2.

\section{Introduction}

There is still a trend in Latvia where inhabitants tend to move from less developed areas to more developed ones, including to foreign countries, thus reducing the development opportunities of the least developed areas even more, the state loses both human capital and tax revenue. Moreover, the disparities between cities and regions are growing up. One of the main problems in Latvia is high youth unemployment. For example, according to the Central Statistical Bureau, the unemployment rate in Latvia at the beginning of 2018 was $7.4 \%$, including $11.7 \%$ for those aged $20-24$ and $9.6 \%$ for those aged 25-29 (Unemployment rate, 2018). One of the reasons of low employability - a mismatch among education programmes, students' skills developed and market needs. Studies in higher education institutions are orientated to a theoretical background and lack practical skills development. There is low integration and collaboration between the business and education sectors. Youth faces many difficulties when trying to enter the labour market. It is because of lack of experience, insufficient vocational education, inadequacy between professional education and requirements for specialists in the job market. Taking into account the regional socioeconomic development and youth employment challenges, it is necessary 
that students get competencies and skills needed for the labour market and increase their employment possibilities. Rezekne Academy of Technologies in cooperation with Northern Lithuania College (Šiauliai) implemented an INTERREG Latvia - Lithuania project "SalesLabs for employability competencies development", which included the integration of problembased learning into study courses.

The aim of the research study is to investigate problem-based learning experiences among students and lecturers.

Tasks of the research:

- describe a problem-based learning approach;

- $\quad$ provide insight into the progress of the project;

- based on the results of the survey, to analyse the experience of students and lecturers in the practical implementation of the problem-based learning method;

- draw conclusions and make proposals.

Novelty of the research - an analysis of students' and lecturers' experience gained while implementing the problem-based learning method in Rezekne Academy of Technologies.

Research methods - the monographic method, the sociological research method - survey.

The research period - 2017-2019.

The research hypothesis - problem-based learning from the viewpoint of students and lecturers - is more exciting than traditional learning, but it is also more time consuming and expertise intensive.

\section{Characterization of problem-based learning}

Problem-based approaches to learning have a long history. This approach was first developed in medical education in the 1950s. The adoption of PBL in higher education outside the medical field throughout the 1990s. PBL are one of many instructional approaches that situate learning in a meaningful task, such as case-based instruction and project-based learning. In the traditions of Kilpatrick (1918, 1921) and Dewey (1938), these approaches argue for the importance of practical experience in learning. Problem-based learning (PBL) is part of this tradition of meaningful, experiential learning. In PBL, students learn by solving problems and reflecting on their experiences (Barrows and Tamblyn, 1980). PBL is well suited to helping students become active learners because it situates learning in real-world problems and makes students responsible for their learning. It has a dual emphasis on helping learners develop strategies and construct knowledge (Cognition and Technology Group at Vanderbilt, 1997; Collins et al., 1989; Hmelo and Ferrari, 1997; Kolodner et al., 1996). 
Educators are interested in PBL because of its emphasis on active, transferable learning and its potential for motivating students (Hmelo-Silver, 2004).

The primary goal of PBL is to enhance learning by requiring learners to solve problems. It is a methodology with the following characteristics (Spector et al., 2008):

- It is problem focused, such that learners begin learning by addressing simulations of an authentic, ill-structured problem. The content and skills to be learned are organized around problems, rather than as a hierarchical list of topics, so a reciprocal relationship exists between knowledge and the problem. Knowledge building is stimulated by the problem and applied back to the problem.

- It is student centred, because faculty cannot dictate learning.

- It is self-directed, such that students individually and collaboratively assume responsibility for generating learning issues and processes through self-assessment and peer assessment and access their own learning materials. Required assignments are rarely made.

- It is self-reflective, such that learners monitor their understanding and learn to adjust strategies for learning.

- Tutors are facilitators (not knowledge disseminators) who support and model reasoning processes, facilitate group processes and interpersonal dynamics, probe students' knowledge deeply, and never interject content or provide direct answers to questions.

The key to problem-based learning is a good definition of the problem. The characteristics of good PBL problems that transcend fields (Duch, Groh, and Allen, 2001):

- The problem must motivate students to seek out a deeper understanding of concepts.

- $\quad$ The problem should require students to make reasoned decisions and to defend them.

- The problem should incorporate the content objectives in such a way as to connect it to previous courses/knowledge.

- If used for a group project, the problem needs a level of complexity to ensure that students must work together to solve it.

- If used for a multistage project, the initial steps of the problem should be open-ended and engaging to draw students into the problem. 
The PBL learning process normally involves the following steps (Spector et al., 2008):

- $\quad$ Students in groups of five to eight encounter and reason through the problem. They attempt to define and bound the problem and set learning goals by identifying what they know already, what hypotheses or conjectures they can think of, what they need to learn to better understand the dimensions of the problem, and what learning activities are required and who will perform them.

- During self-directed study, individual students complete their learning assignments. They collect and study resources and prepare reports to the group.

- Students share their learning with the group and revisit the problem, generating additional hypotheses and rejecting others based on their learning.

- At the end of the leaning period (usually one week), students summarize and integrate their learning (Spector et al., 2008).

\section{Implementation of the project "SalesLabs for employability competencies development"}

Rezekne Academy of Technologies in cooperation with Northern Lithuania College implemented the INTERREG Latvia - Lithuania project "SalesLabs for employability competencies development". The duration of the project was 24 months, and it was implemented from 01.07.2017. to 30.06.2019. Within the framework of the project, 10 courses of Rezekne Academy of Technologies (Marketing, Marketing Communications, Computer Engineering, Project Management, Media Language and Genres, Clothing Design, Interior Design and Ergonomics, Robotics Practice, Software Engineering, Food Commodity Science) were transformed and implemented using problem-based learning. The existing PBL teaching method focusing on hands-on sessions was enhanced with real-world situations from regional businesses by making their new products or services more available to the market (The Concept of SalesLabs..., 2017)

As this method has been used in the study process for several years by Siauliai University, the lecturers of Rezekne Academy of Technologies and Northern Lithuania College were successors and took part in trainings led by the Lithuanian representatives. At the end of the training, the curricula of the courses mentioned above were modified, and the training of students was started by integrating problem-based learning into the study processes in both higher education institutions. Within the framework of the project, transnational workshops were organized, where entrepreneurs shared their entrepreneurial experience with tutors and students with the problems to be 
solved during the study. The students visited the companies, got acquainted with the production of the products, elaborated and defended their proposals for better product commercialization, presenting them to the entrepreneurs and teachers of both countries. There were also experience exchange trips to both neighbouring countries' universities where students, teachers and entrepreneurs had the opportunity to share solutions among various territories of origin and different fields of subjects for one case study, providing interdisciplinarity for the companies involved in the project.

Overall, 32 courses delivered for 350 students during three semesters from Autumn 2018 to Spring 2019. During this cooperation, sixty-four entrepreneurs have received developed solutions to several economic problems (34 in Latvia +30 in Lithuania). As a result, twenty study courses in both countries were improved. The project's internal questionnaires confirmed positive attitude from students, their tutors, and entrepreneurs. Tutors used a different approach to the problem-solving practices for selecting and grouping companies with students: one company - one group, one problem - many groups that was typical for applied and social science disciplines. The most advanced choice: one company - mixed groups. The added value of topicality of the interdisciplinary approach offered abilities to perceive thoughts, things, phenomena which may look completely different and unite them into common, new forms, according to the co-authors of other work (Strods, et al., 2019).

\section{Analysis of survey results}

At the end of the project, in May 2019, a survey was conducted to evaluate the results of the project - the practical implementation of problembased learning. Two questionnaires were developed and distributed.

The first group of respondents were students, who were also the biggest beneficiaries of the project activities. The questionnaire was completed by 67 respondents, covering all the study courses and student groups involved in the project.

The following answers were given to the question "Describe the task your group did in the SalesLabs course?": "New product development", "Packaging concept development", "Market research in Germany, the Baltic States, the Scandinavian countries", "Sketches, a prototype - a clothing design study course", "improvement of the dairy production process: filling of dairy products in packaging, labelling on packaging, a whey separation machine", "improvement of the biscuit production process - a conveyor", "research and application development of marketing communications", "new advertising ideas", "Recommendations for attracting new customers", 
"booklet design", "banner design", "style book design", "office interior design", etc.

The given answers show that students were mainly involved in new product development process and its market uptake enhancement, that is of greater interest for students.

To the question "What were the main difficulties you encountered in the process of developing the solution?" , students responded that "there were problems with scheduling and time constraints", "there were problems with access to information", "language barrier - market research in Germany, Scandinavia", "group incoherence, differences of opinion, unequal group participant initiative", "they had to employ creativity that was not easy", "had to engage in a lifestyle to better understand entrepreneurial desires", "had difficulty selecting only vegan friendly products", "a great challenge was the combination of flavours - study logistics", "It was difficult to get the idea started", "lack of experience in solving such a problem", "difficulty in finding the most cost-effective solution", etc.

The respondent's answers show lack of soft skills and difficulties to work in groups.

To the question "Describe your personal benefits of participating in the SalesLabs project", students gave the following answers: "great experience in communication with the company", "insights into the business processes of large companies", "learned to think more and collaborate", "presentation experience", "experience in market research", "improved teamwork skills", "gain technical skills", "learn to work with an entrepreneur", "gain experience in brainstorming, discussion, problem solving", "ideas leading to prototype development", "mastering modelling", "communication skills", "learning to work in a team - work scheduling and task allocation", "a different view of theory used in practice", "understanding approbation of ideas", "experience in the profession being learned", etc.

The main personal benefits of the students participated in PBL learning were increase of soft skills, recognition of selected career and profession and involvement in new product development processes.

In the questionnaire, respondents were asked to rate a study course that was delivered using problem-based learning on a number of criteria. Summarizing the answers of all the respondents, the average score was calculated as a result. (Table 1 and Figure 1). From the table it can be concluded that the students appreciated the lecturer's presence and support (4.6), which is explained by the fact that the lecturers also had new experience and felt a great responsibility for solving the problem to be presented at the end of the study course to the businessman, as well as the significance of knowledge persistence (4.3) and the role of the team (4.3) as it was also approved previously in the students survey as the rise of students 
soft skills and acknowledgment of selected career as well as new product development as part of it.

Table 1 Evaluate the implementation of the SalesLabs study course against the following criteria (5-highest rating; 1 - lowest rating) (created by the authors)

\begin{tabular}{|l|c|}
\hline \multicolumn{1}{|c|}{ Criterion } & $\begin{array}{c}\text { Average } \\
\text { rating }\end{array}$ \\
\hline Content competences (theoretical knowledge acquisition) & 4.0 \\
\hline Cognitive, technical, competence (practical skills and competences) & 4.1 \\
\hline Attitudinal competences (values, motivation and will) & 3.9 \\
\hline $\begin{array}{l}\text { Knowledge persistence (Will the acquired competences remain in } \\
\text { memory, will not be lost?) }\end{array}$ & 4.3 \\
\hline $\begin{array}{l}\text { Matching competences to the needs of entrepreneurs, real working } \\
\text { conditions }\end{array}$ & 4.1 \\
\hline Work organization & 3.7 \\
\hline Practical application of course knowledge & 4.1 \\
\hline Tutor support & 4.6 \\
\hline Quantity and variety of information sources used & 4.0 \\
\hline The role of the team in achieving the result & 4.3 \\
\hline
\end{tabular}

On the other hand, work organization was the least valued (3.7), which was mentioned earlier in the students' answers that they had difficulties both with time planning and with their personal and group work organization.

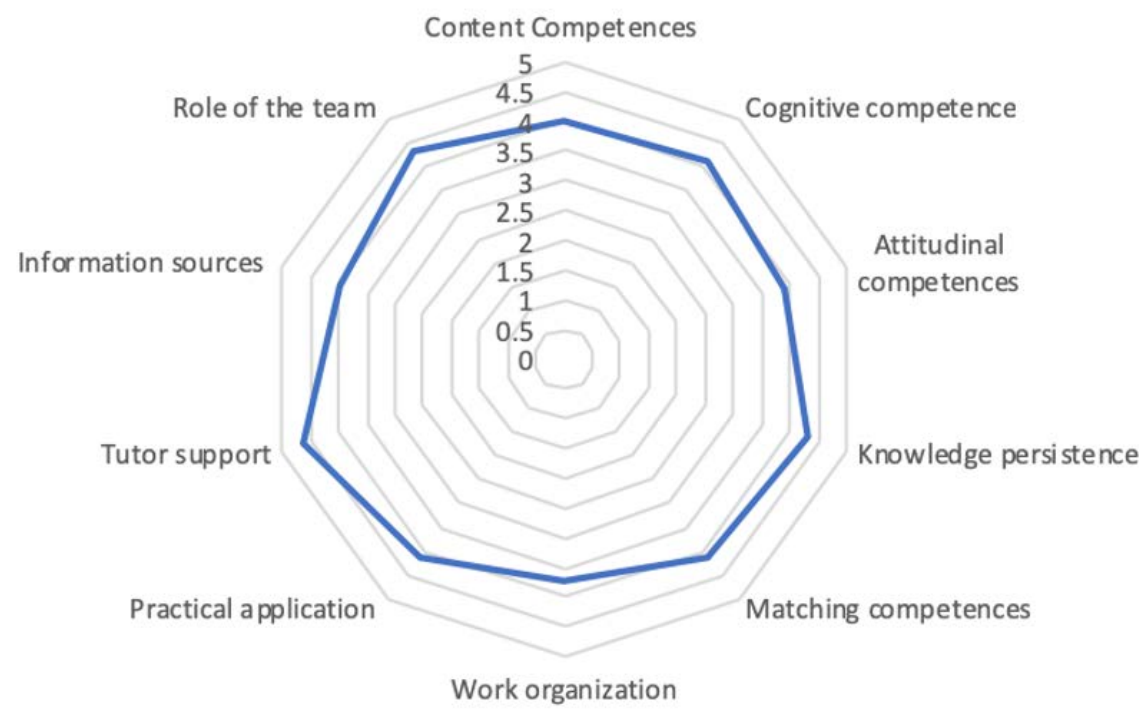

Fig.1 Evaluate the implementation of the SalesLabs study course against the following criteria (5-highest rating; 1- lowest rating) (created by the authors) 
To the question "Compare studying within a SalesLabs course versus traditional study courses", the students responded that "it is an opportunity to work with a real company and the sense that the result can be useful", "give more insight into the chosen profession", "problem solving is better than writing reports", "much more effective", "much more interesting", "traditional studies are more understandable, do not require much personal time, know theories and are sufficient", "invest a lot more work and time", "enable practical application of knowledge", "being able to see a real problem in companies", "such studies stimulate interest, nonstandard thinking and teamwork skills" etc.

From the answers can be seen that students highly appreciate the new study method as interesting and effective, but also mention that requires more time and effort.

To the question "Did you also gain any personal insight into your chosen future career?", the students responded: "I understood the need to work harder and set personal tasks", "I have chosen the right career marketing", "I realized that I am interested in this profession, I doubt so far", "I realized that in the future I could work not only as an interior designer but also in the advertisement industry" and so on.

The given answers show that this study method opens new career possibilities and motivate students to learning.

To the question "What should be improved / changed by the new methods in the learning process?", the students responded that "more study courses should be implemented by this method", "provide motivation to students by highlighting the benefits of the project", "meet business people more often" and so on.

The main improvement of the SalesLabs study method is practise it more expanding it to other study courses too.

The second group of respondents were lecturers actively involved in the implementation of the project activities. The questionnaire was filled out by 10 respondents, that is, all the lecturers involved in the project, representing Rezekne Academy of Technologies.

The lecturers were asked the question "Evaluate objectively the extent to which students succeeded in achieving the entrepreneur's expected problem-solving results". The opinions of the lecturers differed in their answers: some lecturers stated that students succeeded in solving the problems expected by the entrepreneur, as evidenced by the work result or the product itself, which was acknowledged during the meeting with the entrepreneurs. The other part of the lecturers admitted, however, that students failed to reach the solution expected by the entrepreneur. The result was influenced by how precisely the entrepreneur was able to formulate the problem (task) to be studied by the students, how well the solution was 
executed qualitatively, especially in the situation when a creative solution was needed.

To the question "What were the main difficulties (if any), why did you fail to achieve the expected $100 \%$ result?" The lecturers mentioned the following factors: "unequal distribution of the workload in student work groups (students themselves are not always able to allocate tasks) each student's personal contribution influenced the overall score", "the student activity could have been greater. The students were regularly encouraged to work, improve and supplement things. The students seemed to have the minimum, but in order to achieve a better result, communication and followup had to be done during the assignment", "Initially, students had difficulty working in groups and thus responsibilities were split so that everyone could work individually at home. This shows that today students prefer to work individually using communication technologies", "including the lack of task deadlines, where students had to be given specific deadlines on a regular basis, otherwise there was no motivation to tackle the task", "The quality of the solutions offered depends on the abilities, creativity, willingness of students of particular groups", "students were offered the opportunity to go on field trips to companies, interview entrepreneurs / specialists, but not every student used this opportunity", "too small groups - 2-3 students", "students are not experienced in technical tasks", "low level of daring" etc.

The given answers show previously mentioned need for soft skills training for students and division of students into groups required more attention from tutors to provide equal groups as the bases for competition and greater engagement from students groups.

To the question "What would need to be improved / changed in the existing method to make it more solution-oriented and help to achieve results more effectively?" the lecturers noted that: "changes occur every time the lecturer starts to implement the study course because the problem differs, another company and other students with a different level of knowledge and skills", "mix students from other course subjects for seeking a solution by one company could give more insights into group work and lead to better results", "students' motivation should be ensured. One way to improve that is to give one assignment to different groups so that they have to compete", "organize student work so that there are not many parallel lectures at this time, many other tasks prevent it from being fully addressed", "there should be multiple auditoriums that can be used for work with groups using PBL", "improved feedback from companies and student groups is needed. This could find the form of meetings where work-related details are discussed, the company would be able to respond to students' questions, provide advice", "engage students more actively. The lecturer must be able to encourage students to learn more about themselves, not to say the right 
answers or lead them too openly to the intended problem", "increase the study course volume. More time should be devoted to the preparation of the course - to choose the situation, to produce handouts or visuals, and to anticipate the discussion. This method takes much longer, so it is not possible to use it if the time allotted for teaching is too short. The best format would be: lectures in two, three days a week", "the situation would certainly be improved by a greater number of students involved and multi-group work where multiple solutions could be developed", "provide funding for prototype development", "more attention from the lead" and so on. From the given answers can be concluded that interdisciplinary problem based learning when one company is served with students from different study courses can rise greater awareness and lead to students competition and engagement, implementing equal division int working teams.

\section{Conclusions and suggestions}

Traditionally, studies in higher education institutions are oriented towards a theoretical background and lack practical skills development, and there is still low integration and collaboration between the business and education sectors. When acquiring higher education, young professionals often face problems in the labour market, such as a lack of experience, inadequate competences for the employer, and a lack of skills to deal with real business problems.

Problem-based learning has long been widely used throughout the world, providing young people with an understanding of the real world of work and the challenges of their chosen profession, helping them to understand the relationship between theory and practice, and integrating it successfully into higher education. Lecturers and students of Rezekne Academy of Technologies also gained such experience, integrating problembased learning in 10 different study courses.

Overall, it can be concluded that lecturers 'and students' experience of problem-based learning is positive, it is considered more effective and exciting than traditional learning, but it is also more time consuming and top expertise-intensive.

As problem-based learning can be integrated into courses in different fields of study, Rezekne Academy of Technologies would also recommend finding ways to integrate this teaching method in other study courses. At the administrative level, it is required to find solutions concerning facilities, lesson planning, and collaboration with business to ensure the effective use of this method in the study process.

More attention to the division of students into groups should be allocated. During lectures on theory, teachers should divide leaders with soft 
skills and competences into equal groups to provide natural competition among classmates.

Providing one company for different course subjects even with a different problem defined can provide interdisciplinary benefits to the learning and teaching of the new generation (Generation $\mathrm{Z}$ ) of students. A separate study should be addressed for testing of self-directed learning evaluations of PBL students versus traditional learning in higher education.

The Concept of Sales Laboratories in the learning and teaching process in higher education can be seen as a business support instrument for certain problem solving in entrepreneurship and innovation policy development at regional levels.

\section{References}

1. Barrows, H.S., Tamblyn, R. (1980). Problem-Based Learning: An Approach to Medical Education, Springer, New York.

2. Bezdarba līmenis (2018). Centrālās statistikas pārvaldes datubāze. Retrieved from http://data1.csb.gov.lv/pxweb/lv/sociala/sociala_nodarb_bezdarbs_ikgad/?tabl elist=true

3. Hmelo-Silver, C.E. (2004). Problem-Based Learning: What and How Do Students Learn? Educational Psychology Review, Vol. 16 (3), pp. 235 - 265.

4. Cognition and Technology Group at Vanderbilt (1997). The Jasper Project: Lessons in Curriculum, Instruction, Assessment, and Professional Development, Erlbaum, Mahwah, NJ.

5. Collins, A., Brown, J. S., and Newman, S. E. (1989). Cognitive apprenticeship: Teaching the crafts of reading, writing, and mathematics. In Resnick, L. B. (ed.), Knowing, Learning, and Instruction: Essays in Honor of Robert Glaser, Erlbaum, Hillsdale, NJ, pp.453-494.

6. Dewey, J. (1938). Experience and Education, Macmillan, New York.

7. Duch, B. J., Groh, S. E, \& Allen, D. E. (Eds.). (2001). The power of problem-based learning. Sterling, VA: Stylus.

8. Hmelo, C. E., and Ferrari, M. (1997). The problem-based learning tutorial: Cultivating higher-order thinking skills. J. Educ. Gifted, Vol. 20, pp. 401-422.

9. Kilpatrick, W. H. (1918). The project method. Teach. Coll. Rec, Vol. 19, pp. 319-335.

10. Kilpatrick, W. H. (1921). Dangers and difficulties of the project method and how to overcome them: Introductory statement: Definition of terms. Teach. Coll. Rec, Vol. 22, pp. 282-288.

11. Kolodner, J. L., Hmelo, C. E., and Narayanan, N. H. (1996). Problem-based learning meets case-based reasoning. In Edelson, D. C., and Domeshek, E. A. (eds.), Proceedings of ICLS 96, AACE, Charlottesville, VA, pp. 188-195.

12. SalesLabs for employability competencies development/Nodarbinātības kompetenču uzlabošana pārdošanas laboratorijās (2017). Retrieved from https://www.rta.lv/citi_projekti?project_id=96

13. Spector, J. M., Merrill, M.D., Jeroen van Merriënboer, Driscoll, M.P. (2008). Handbook of Research on Educational Communications and Technology (3 ${ }^{\text {rd }}$ ed.) Lawrence Erlbaum AssociatesTaylor \& Francis Group

14. Strods, G., Igavens, M., Tandzegolskiene, I., Shevtshenko, E. (2019). Implementing Interdisciplinarity in Career Guidance. Guidebook for career counselors, Tallinn. 